\title{
Not Suspended but Not Protected: Challenging School Discipline Reform in the Name of Restorative Justice for Young Adult Black Girls
}

lesha Jackson

University of Nevada, Las Vegas, iesha.jackson@unlv.edu

\section{Recommended Citation}

Jackson, lesha (2021) "Not Suspended but Not Protected: Challenging School Discipline Reform in the Name of Restorative Justice for Young Adult Black Girls," Northwest Journal of Teacher Education: Vol. 16 : Iss. 2 , Article 4.

DOI: https://doi.org/10.15760/nwjte.2021.16.2.4

This open access Article is distributed under the terms of the Creative Commons Attribution-NonCommercialShareAlike 4.0 International License (CC BY-NC-SA 4.0). All documents in PDXScholar should meet accessibility standards. If we can make this document more accessible to you, contact our team. 


\title{
Not Suspended but Not Protected: Challenging School Discipline Reform in the Name of Restorative Justice for Young Adult Black Girls
}

\begin{abstract}
This interpretive case study examines the impact of one high school's mediation process, which is intended to be a restorative practice, on the schooling experiences of three "overage, under-credited," young adult Black girls. Using critical race theory, this study explicates how the school's approach to mediation fails to protect these students from both physical and structural violence. While it is important that the findings lay a foundation for understanding the contexts of anti-Blackness in restorative practices in schools, insights from this study can also help establish culturally and contextually specific approaches to mediation for young adult Black girls in high schools.
\end{abstract}

\section{Keywords}

Anti-racism, Black girls, school-based mediation, critical race theory

\section{Creative Commons License}

cc) (i) (2)

This work is licensed under a Creative Commons Attribution-NonCommercial-Share Alike 4.0 International License. 


\section{Introduction}

Throughout the United States education system, Black girls are disproportionately impacted by the criminalization of Blackness in schools. Morris (2012) emphasizes aspects of objectifying Black girls that delimit appropriate behavior into norms of whiteness, or performing femininity in a demure, quiet, and cooperative manner. Such objectification exemplifies anti-Blackness (Dumas \& Ross, 2016) as it disregards if not disdains the myriad ways Black girls show up in schools. When Black girls assert themselves outside of standards of whiteness, they are more likely to be reprimanded or suspended. During the 2015-2016 school year, Black girls lost 1.7 million days of instruction due to suspension, a rate twice as high as the national average for all students (Losen \& Whitaker, 2020). To address this disparity and potentially counter certain forms of antiBlack policing in schools, restorative justice practices are gaining traction as alternatives to punitive discipline. However, Black girls are rarely consulted to understand the brunt of such policies.

This article examines the impact of one high school's mediation process, which is intended to be a restorative practice, on the schooling experiences of three young adult Black girls. Using critical race theory (CRT) as both a theoretical and analytical framework, this study applies tenets of racial realism (Bell, 1992), intersectionality (Collins, 2019), counterstorytelling (Dixson \& Rousseau Anderson, 2018), interest convergence (Bell, 1995), and structural determinism (Delgado \& Stefancic, 2012) to understand how the school's approach to non-punitive discipline through mediation fails to protect young adult Black girls from both physical and structural violence. I draw on Jenkins's (2021) notion of schools as sites of spatialized terror in relation to CRT to explore the following research questions:

- What are students' perspectives of the school's climate related to safety for young adult Black girls?

- When mediation is required, how do participants experience the process? Jenkins (2021) argues that schools are places where Black youth routinely experience systemic, physical, symbolic, linguistic, curricular, and pedagogical anti-Black violence as an outgrowth of the design of public education. While it is important that the findings lay a foundation for a deep understanding of the contexts of anti-Blackness in restorative practices, I also use insights from this study to posit what establishing culturally and contextually specific approaches to mediation might entail for young adult Black girls in high schools. 


\section{Mediation as an Alternative to Punitive School Discipline}

Falling under the umbrella of restorative justice and often articulated through legal definitions, mediation can be understood as a process whereby an impartial third party facilitates a mutually agreed upon resolution to a dispute between two opposing parties; essential to the process is voluntary agreement as determined by the two disputing parties (American Arbitration Association, 1997). Mediation practices typically begin with training the mediator in communication and negotiation skills. Such trainings might be provided by community organizations, professionals in the field of conflict resolution, or school counselors and staff; training can also provide mediators with explicit scripts to follow in conversations with disputants (Lindsay, 1998; Nix \& Hale, 2007).

Whether facilitated through counselors, teachers, or peers, school-based mediation is viewed as a positive alternative to exclusionary discipline practices (Dettwiller, 2019). The argument is that by incorporating tools for resolving conflict, mediation can not only prevent disagreements from becoming violent altercations but also foster a relationship-based school culture in which students meaningfully contribute to the community (González, 2012; Klein, 2016; Morrison, 2005). While studies on school-based mediation have demonstrated effectiveness in reducing violent incidents on campus and improving school climate, research that includes an analysis of the resolutions reached through mediation indicate that the results are often short-term and superficial (see Johnson \& Johnson, 1996).

Through the lens of anti-Blackness, these practices can be viewed as a misguided attempt to make schools safer without considering the emotional burden students carry during and after the process. In describing schools as sites of spatialized terror, Jenkins (2021) details how "violating the social order shapes the spatiality of contemporary education policy and practice" (p. 6). This is particularly important in the context of mediation because it is often mandated before any official school rule is broken. For example, two Black girls can argue in a hallway before school. If they are deemed to be loud, aggressive, or confrontational (all examples of microaggressions wielded against Black girls to control their behavior; see Morris, 2007), they can be required to participate in mediation because of a perceived threat of escalation. As examples of the publicly known murders of Black men, women, boys, and girls evinces (George Floyd, Breonna Talyor, Tamir Rice, and Aiyana Stanley-Jones to name a few from a growing list), Black people are too often perceived as a threat. Based on this perception, Black students are surveilled in schools through what Parker (2017) defines as secondary policing or the hyper-surveillance of Black youth that "poses a philosophical and pragmatic issue for educators" (p. 1) to challenge their deficit notions of Black people, particularly students. 
Furthermore, few studies on mediation include Black students' perspectives of the process. As a Black woman and teacher educator, I am personally invested in amplifying the voices of Black girls in conversations around school reform. I believe that if educators, policymakers, and community members are to create humanizing educational environments for Black girls, they must listen to, learn from, and follow the lead of this student population. To date, there is limited scholarship that considers young adult Black girls' experiences of restorative justices approaches such as mediation (see Morris, 2019). Therefore, there is a need to understand the impact of mediation on their schooling experiences in order to more fully analyze the various impacts of anti-Blackness in so-called restorative practices.

\section{Critical Race Theory as Theoretical Framework and Analytic Tool}

Particularly as it relates to education, critical race theory (CRT) exposes and counters deficit notions that blame students of color for underachievement and/or dropping out of school; critical race theorists reject analyses of academic achievement and schooling experiences that do not acknowledge the endemic nature of racism in the U.S. (Tate, 1997). Foundational to CRT scholarship is the assertion that the systems and institutions of the United States are so deeply imbued with racists ideologies that racist practices appear normal. Stated differently, the impact of unequal stratification of society based on race and racism is rendered invisible without frameworks such as CRT that intentionally bring racism to the forefront of analyses. Furthermore, critical race scholars argue that race-neutral rhetoric can mask systemic efforts to perpetuate racial inequalities (Solórzano \& Yosso, 2002) rooted in anti-Blackness (Coles \& Powell, 2020).

This study engages the following tenets of CRT:

- Racial realism: the belief that racism is permanent and cannot be fully eradicated through civil rights laws. Not intended to be defeatist, "racial realism insists on both justice and truth" which is to say the truth that although racism cannot be legally redressed, justice is still possible (Bell, 1992, p. 92). Racial realism is foundational to analyzing meditation as an anti-Black policy "propelling Black urban youth to see the inequity and violence facilitated by anti-Blackness as a wrongdoing on their end" (Coles \& Powell, 2020, p. 23).

- Intersectionality: accounting for multiple bases of identity within the construct of the social world (Crenshaw, 1991). Explored in this article are the intersections of race, gender, and age as they shape the ways three young adult Black girls experience and make sense of mediation at their 
school. As I discuss later, the participants in this study were 18 years old and older, which has specific implications for this work.

- Counterstorytelling: used interchangeably with counternarrative (Dixson \& Rousseau Anderson, 2018), counterstorytelling is "a method of telling the stories of those people whose experiences are not often told" (Solórzano \& Yosso, 2002, p. 32). The coding and themes generated in the analysis process serve as means of creating counterstories, and the meaning making includes direct quotes from participants as often as appropriate. For this study, I incorporate counterstorytelling to highlight the lived experiences of students of color who have historically been marginalized in educational discourse.

- Interest convergence: the belief that opportunities for marginalized groups are only possible to the extent that they converge with the interests of dominant groups with social and political capital (Bell, 1995). Through interest convergence, I highlight the ways in which mediation serves the interests of the school professionals without actually protecting young adult Black girls from violence.

- Structural determinism: the argument that institutions such as schools are not equipped to remedy certain kinds of social wrongs, such as racism (Delgado \& Stefancic, 2012). The purpose of examining evidence of structural determinism in this study is to explore how attempts at reforming school policies to include mediation might fail to protect young adult Black girls.

I use these tenets of CRT to assert that the United States is "an anti-Black society which implicates all people, structures, and institutions within it" and add this scholarship to research that "center[s] the Black voice specifically in research that aims to address and dismantle the violence of antiblackness" (Coles \& Powell, 2020 , p. 118). From this, I analyze personal and institutional implications of mediation as a mechanism for protecting whiteness in schools at the expense of young adult Black girls.

\section{Research Context and Methods}

Data are from a larger case study on the schooling experiences of overage, undercredited (OA/UC) Black students at a transfer high school in New York City (NYC). Students can be labeled OA/UC if they are two or more years behind their peers in terms of both age and credits earned towards graduation. Transfer high schools in NYC are "small, full-time high schools designed to re-engage students" by offering rigorous academic learning opportunities alongside college and career planning (NYC Department of Education, 2021, para. 1). The school in this study, referred to as Seeds of Promise High School (SPHS), accepts students who range 
in age from 16 to 21 years old. During the academic year in which data for the study were collected, the student population was approximately $40 \%$ Black with female students accounting for just over $50 \%$ of the total student body (New York State Department of Education, 2015). To enroll, students must be at least 16 years old, have attended a traditional high school for at least one year, and complete an application process that includes an interview with a parent/guardian and school faculty member. The young adults who attend this school largely come from three of NYC's five boroughs. Due to their status as overage and undercredited, the students at SPHS come to school having faced academic and/or personal challenges resulting in a need to recover credits faster than would be possible in a traditional high school setting. The school endeavors to provide a student-centered, family atmosphere in which supportive relationships, selfdetermination, and collaboration are paramount to the school's culture (SPHS Principal, Personal communication). This articulation of the school's culture is aligned with the theoretical foundations of conflict management through mediation. Yet, data analysis in this study suggests that there are unintended and often invisible consequences of mediation for young adult Black girls.

Methodologically, this research is an interpretive case study (Yin, 2009). The interpretive tradition of qualitative research assumes that individuals construct meaning through interactions with others and with contexts (SchwartzShea, 2006). This assumption grounds my belief that the context of the school, particularly its culture and mediation practice, significantly shapes Black students' educational experiences. Moreover, this methodological approach complements CRT as a theoretical framework and analytic tool to expose elements of anti-Blackness participants experience through the school's meditation process.

\section{Participants}

Karma, Monica, and Evelyn (18, 19, and 20 years old respectively) are the three young adult Black girls who participated in this study. Collectively, they had previously attended a total of eight high schools, and their credits towards graduation at the start of the study ranged from 11 to 38 out of 44 required. Evelyn and Karma had been enrolled at SPHS for five semesters at the start of the study while Monica was in her third semester. Overall, the three young adult Black girls had distinctive experiences at SPHS and felt differing levels of support from school professionals. For example, Karma was the most involved in school clubs including the student advisory board that met with the principal weekly. She spoke highly of the school climate as well as teachers and administrators during our initial interview. Conversely, Evelyn said being "left back" in junior high school contributed to her coming to SPHS as an OA/UC student, but she 
"changed [her] life around" once she got to SPHS. She developed the attitude that, "if you tell me what to do [academically], I'll do it" adding that she didn't need much support or encouragement from her teachers. Finally, Monica disapproved of the school climate, noting that when she enrolled, she did not feel welcomed. In her relatively short time at the school, she experienced challenges getting along with her peers and relating to her teachers. She was the only girl to leave SPHS without graduating.

\section{Data Collection and Analysis}

Data were collected over an eight-month period, spanning an academic year. Data collected include: two rounds of group interviews, classroom and school setting observations, and individual interviews with participants. The first group interview preceded all other data collection methods. Between the two group interviews, I made a total of 12 site visits that included individual interviews and classroom observations of Evelyn and Karma. By the time I conducted individual interviews, I had spent two school days with Evelyn and Karma, shadowing each student in her classes, talking and observing in the hallways during passing periods, and eating lunch with them and their friends. Before I could observe Monica, she withdrew from the school. She did not respond to messages to continue the study; according to Karma, she did enroll in a GED program to continue her education.

To address my research questions, I transcribed audio recordings of all interviews and analyzed the data using CRT tenets as initial codes to categorize chunks of data across participants and data sources. Once compiled, second level codes were used to make meaning from the categories that reflected students' perceptions of their schooling experiences. In the following section, I detail a portion of the findings specifically related to the young adult Black girls' views of the school climate and the process of mediation. An underlying theme of these data was the notion of safety. In talking about creating safe spaces for dialogue about race, Majors (2015) writes,

It is common to put the condition of 'safety' around public race dialogue as a procedural rule in education. Like brackets, such a condition maintains 'comfort zones' while at the same time inflicting what is a persistent and symbolic form of violence experienced by people of color. The question (or rather the elephant in the room) remains, safe to whom? (p. 114)

These ideas are central to how I frame students' experiences of mediation. Tenets of CRT are used to elucidate processes that are intended to create "safe spaces" 
for students while safety becomes more about keeping the school space "safe" or free from violence and without proper regard for the students themselves.

\section{Findings}

The conversations I had with Evelyn, Karma, and Monica suggest that overage, under-credited Black girls are not only not protected through so-called restorative practices like mediation but worse, they are likely to suffer from a form of spatialized terror when the school's attempts to mediate conflict only "make things worse" as Evelyn states. They talked at length about the difficulties young adult Black girls at the school have getting along with one another and the impact of mediation.

\section{“Girls Bring More Drama": Gender, Conflict, and Coping Strategies for Drama}

Evelyn, Karma, and Monica were vocal about gender issues at their high school. They viewed other young adult Black girls at the school as "emotional" and "bring[ing] drama" which deleteriously affected their relationships with their peers on campus. During the first group interview, Karma and Monica shared that they do not like some of the girls at the school. In contrast to the way they perceived their male peers interacting, Monica stated, "I honestly think that...boys get along with each other more than girls. I mean it's hard for females to interact with each other." Karma added, "Some females have bad attitudes" before Monica continued with:

But like, boys is different. They'll probly play basketball. That's probly how they meet up. I don't know, me-I'm a nice person. I have a nice personality...you don't always find that in some girls.

Although the school offered a leadership program for a small group of girls in addition to a short-lived school club started by Karma to bring girls together, the young adult Black girls felt like there was a lack of unity, respect, and understanding among girls at the school which contributed to conflict in daily interactions. The presence of, or potential for, regular conflict at school can create threats to students' mental well-being that often go unnoticed by school professionals (Watson, 2016). This form of misrecognition "invisibilizes antiBlackness" (Coles \& Powell, 2020, p. 2) by reifying harmful notions of strong Black (young) women who are built to endure drama or emotional unrest. Evelyn's view was, "It's just so...so much petty drama that goes on in SPHS. It makes no sense with these females." Knowing that they would be expelled from school if they were to fight on campus, the young adult Black girls had to 
maneuver the social environment at SPHS with a level of restraint when drama arose. Amid persistent drama between girls at the school, Evelyn, Monica, and Karma experience a particular type of structural violence, the everyday suffering (see Dumas, 2014) of marginalized Black girls whose collective injury is invisible or trivialized within the culture of the school. Despite the school's efforts to create a family oriented, supportive environment, the participants had to enact a resiliency that allowed them to negotiate their educational context in the face of persistent conflict. They did not feel particularly supported in this process at the school.

The school has a zero-tolerance policy regarding fighting on campus; any act of physical violence at SPHS automatically results in expulsion. As a transfer high school for students who are too far behind in credits to graduate from a traditional high school yet have likely been to multiple high schools before enrolling, the policy inadvertently forces students to develop strategies for mitigating conflict without violence. In this way, the interests of both the students and the school are served to create an atmosphere where students rarely if ever engage in violence at school. However, the zero-tolerance policy does not address conflict between students before it escalates to violence. All three participants discussed how they approached conflict at school by trying to ignore "petty" issues. Karma explained:

I try to ignore ignorance. It's like, my motto is, 'Never forget the word ignore is in the word ignorance.' So, it's like, that pushes me to ignore your stupidity, your arguments over nothing like, why we arguing when we in a school where we can't fight? And normally people fight out their anger, so why are we sitting up here arguing over something that's so petty, or why are we sitting up here arguing period?

All three students admitted to resorting to violence in the past both at school and in their neighborhoods. They did not discuss their behavior in terms of what was or was not appropriate for them as young adult Black girls but rather what was necessary to protect themselves. Their social location informs the ways in which they challenge dominant expectations for so-called ladylike behavior (see Morris, 2007). The school's zero-tolerance policy operated as a structural force that regulated their behavior in school and required them to hone skills such as ignoring petty drama or risk facing expulsion if conflicts escalated.

\section{“The Mediation in this School Doesn't Work": Intersectional Understandings of Mediation}


Drawing from Jenkins's notion of schools as sites of spatialized terror, this section details how meditation as conducted at SPHS is not a means to restorative justice; it is merely a mechanism of control that (intentionally or not) creates opportunities for physical and psychic assaults on the young adult Black girls who experience it.

Terror is spatialized in bodies, buildings, minds, classrooms, and other physical locations around schools. It is experienced in the routinized policies, practices, arrangements, and structures that work in tandem to perform the labor of terror. A common misconception of terror is that it is only a linear mechanism and therefore can be traced to a singular cause and effect. However, terror is not only found in the shocking and the terrible, but terror is also experienced in the mundane and quotidian (Hartman 1997). Consequently, the spatialized terror that Black youth experience is a permanent condition of schooling that is inseparable from their everyday realities. (Jenkins, 2021, p. 14)

During my time at SPHS, none of the students involved in this study participated in mediation. Nonetheless, it was a topic of discussion in several interviews. I asked the students to explain how mediation works and talk about a time they had to go through it. After Karma explained that "mediation is for when you havin problems with somebody that could go left [get worse] in a minute," Evelyn and Monica shared the following exchange:

Evelyn: Basically, you have to go and sit with Rebecca [a white woman who is the school's guidance counselor] — Monica interjects: I can't stand her! - And whoever you have a problem with. You're supposta work through everything together, like talk about what's going on. Monica: I was supposta do it once, but I didn't go...I just didn't come to school that week, and when I came back, I met with Rachel [a Black woman who is SPHS's principal] by myself and told her everything was cool [and that] I worked through what I needed to work through.

Anti-Blackness shapes the right to exist and behave in particular ways inside school buildings. At SPHS, the process of mediation is one in which students suspected of being likely to violate certain policies are forced to sit in a room and essentially demonstrate that they can conduct themselves in a manner deemed appropriate by the mediator. One cannot ignore the racial power dynamic present at SPHS when the mediator is a white woman with limited contact with students during the average school day. Typically, Rebecca facilitates the mediation in her 
office, bringing all parties together and having them talk until a resolution is reached; students are not allowed to exit mediation until there is an amicable outcome as determined by the facilitator. Jenkins (2021) posits that "an anti-Black spatial imaginary is suited to reveal the mundane, everyday forms of terror that Black students face" (p. 14). He discusses an "ontological terror" that "foregrounds not only the terror that Black people feel with a lack of security, but also how non-Blacks project terror onto Black bodies" (p. 14); this is useful to explain how some of the young adult Black girls in this study view mediation. Rather than subjecting herself to such terror, Monica skipped school altogether, exposing the potential for mediation to become a push-out factor for students like her.

It is important to restate the premise that, according to the American Arbitration Association (1997), mediation involves voluntary agreement as determined by the two disputing parties. At SPHS, meditation might result in a stated agreement that students volunteer, but such statements do not equate to a resolution. Karma said, "Some students just say [the issue leading to mediation] is over so they can leave [ending the mediation process]. It's not really over; it's just over for that moment." Evelyn acknowledged:

Honestly, the mediation in this school doesn't work. It's not gonna work because you're not gonna stop me from not liking somebody if they made a comment about me. So, the mediation I feel like is making it worse because we're talking about something, nobody knows the truth about it, so, like, why am I here [in mediation]?

The foundations of conflict management models in schools rely in part on the belief that parties in conflict desire mutually beneficial outcomes and enter the resolution process with a willingness to cooperate. However, Karma and Evelyn's perspectives challenge that theory and expose the influence of unequal power distribution in the mediation process. Furthermore, Monica's and Evelyn's experience of not wanting to participate in mediation challenges stereotypical notion of girls wanting to talk through their issues and share their feelings. Young adult Black girls are not always willing participants in the mediation process; they sometimes simply do and say whatever it takes in the meeting to end it as quickly as possible. An unintended and taken for granted consequence of mediation is that it can intensify hostile feelings students have not only about their peers but also about the school and its policies. Keeping students in a room until the mediator deems the issue settled can cause students to feel more upset and powerless. Although previous studies assert the benefits of mediation, the reality experienced by Evelyn, Karma, and Monica is that mediation potentially does more harm than good. 
While effectively curbing violent behavior at school, the mediation process at SPHS does not prevent students from engaging in violent behavior in other spaces. In fact, Monica and Karma revealed that problems young adult Black girls have with each other can result in violence off campus. Karma shared,

Boys laugh at the bullshit. Girls fight over it...girls [pause]—sometimes [physically fight] but not in the building. They take their drama like to the train and like back to Brooklyn. It's like, you just gotta like [pause] just slap the sh-Sugar Honey Iced Tea outta this person.

Despite mediation practices and a school environment where violence is not tolerated, violent acts by and against young adult Black girls are not always prevented. In fact, Evelyn contends, "It's worse when they don't fight at school. It's crazy, like, once they leave SPHS, it just gets worse. More people get involved, and sometimes nobody's there to try to stop it." With students leaving campus and having violent encounters in their communities, there is the added risk of public surveillance (Parker, 2017) that leads to police involvement. The consequences of police involvement for legal adults are potentially harsher, and more importantly, as we know from the cases of Breonna Taylor, Crystalline Barnes, Sheneque Proctor, and Gynnya McMillen (to name a few on a growing list; The African American Policy Forum, n.d.), potentially deadly for young Black women and girls.

\section{Discussion}

This study highlights a tension between the hypervisibility of young adult Black girls at school when they do not adhere to dominant norms of behavior, and the invisibility of their suffering as a result of policies and practices that fail to protect them. Through this work, I assert that "in order for restorative justice to work there has to be an existing community to be restored to" (Wadhwa, 2013, p. 233). SPHS was not a welcoming environment for students like Monica; it is a place where young adult Black girls view their peers as part of the problem because of the drama girls bring. Given this, mediation could not be more than a system of control or conformity that masks anti-Blackness. Redressing anti-Blackness in policies such as mediation will require culturally and contextually specific approaches (see Morris, 2019) to conflict resolution in schools.

\section{Limitations}


It is important to note that the three participants in this study do not necessarily speak for all young adult Black girls at their school. At the same time, their individual and collective experiences are no less valid. In terms of limitations, I acknowledge that the findings of this study could have been more nuanced with additional participants and if Monica had remained at the research site for the entire school year. However, as a qualitative case study, my intent was not to generate findings that could be generalizable to all young adult Black girls in alternative school spaces but to open a conversation about the ways antiBlackness might inadvertently permeate school discipline policies that are viewed by some as restorative. I continue that conversation with implications rooted in my analysis as well as existing literature on liberatory possibilities for Black girls in school (Morris, 2019; Watson, 2016).

\section{Implications}

In this section, I posit what culturally and contextually specific approaches to mediation might entail for young adult Black girls in transfer high schools and align the following recommendations with CRT's tenets of counterstorytelling and intersectionality.

\section{Cultivate Humanizing Environments for Black Girls}

A promising strategy for creating learning environments with the potential to be liberatory for Black girls is to first humanize the various ways these students show up in schools (Evans-Winters, 2007). While some might think this recommendation goes without saying, anti-Blackness as a framework exposes dehumanizing practices that shape everyday schooling experiences for young adult Black girls. To define and cultivate a humanizing learning environment, educators must center the stories and experiences of Black girls in a specific school context. Inviting them to discuss their views of the school in various ways (for example privately, in group settings, anonymously) is one potential starting point for an actionable step teachers might take. The young adult Black girls of this study opened up to me in part because I was genuinely interested in and concerned about how they experienced the culture and climate of SPHS; while the larger study involved both young adult Black boys and girls, I was intentional about creating opportunities for the girls to talk with me together and in individual interviews. Building trusting, caring relationships is also a key component of any humanizing learning environment (McArthur \& Lane, 2019).

\section{Provide Culturally Relevant and Context Specific Professional Development for Mediators}


A major impediment to meaningful mediation at SPHS was the mediator, a white guidance counselor who did not know any of the young adult Black girls in this study well and who Monica expressly disliked. In this school, the mediation process was hindered by Rebecca being a person with whom some students, Monica and Evelyn for example, only meet with when they are called into mediation or when there are concerns about academic progress. In this sense, her role could be viewed as one of policing behavior and academic performance more so than providing guidance or counseling. Considering this, training for mediators should go beyond established expectations for conflict resolution to include preparing educators to understand young adult Black girls' multifaceted ways of knowing and being, cultivating individual relationships with students before conflict arises, and facilitating conversations that allow for student agency. This is particularly important in a transfer school environment where students can be legal adults who might resist school policies and practices that seem more suited for younger learners. Requirements for easy resolutions (staying in an office until everyone asserts the issue is over) should be avoided, especially given the reality shared by participants that the process can exacerbate feelings of anger and frustration which could escalate outside of school.

Teacher educators, counselor educators, school administrators, and professional development providers for in-service teachers can all meaningfully contribute to better preparing mediators and any school staff involved in approaches to restorative justice. As policies for implementing alternatives to punitive discipline expand in schools and districts nationwide, stakeholders involved should first analyze the school context, student perceptions of policies, and providers and implementors of restorative practices such as mediation. This might include surveying students, researching issues that happen outside of school but impact students, and ensuring that professionals who are well-trained in research-based practices for improving schools for young adult Black girls are leading the efforts alongside youth.

\section{Involve Black Girls in School Policy Reviews and Revisions}

Another promising practice for creating school environments that have the potential to counter anti-Black policies is youth participatory action research (YPAR). Evans-Winters (2017) details the transformative potential of YPAR with Black girls who, through the research process demonstrated their agency in "collectively questioning, exploring, engaging, and naming one's own reality" ( $p$. 422). Involving young adult Black girls in a research process to examine, challenge, and revise policies can help educators better understand which policies and practices reinforce the marginalization of these students from their 
perspectives. However, as with the recommendation above, professional development with intimate knowledge of the students and school should be a requisite for any adult facilitating a YPAR process. As Evans-Winters highlights, the positionality and dispositions of the adult co-researcher the framework for engaging, presenting, and ultimately effecting change via the perspectives of Black girls in schools. Therefore, adult co-researchers should be individuals with a critical consciousness around anti-Black schooling and the education of young adult Black girls.

\section{Concluding Thoughts}

Before naming practices "restorative," one might first ask, "what are we seeking to restore?" This question challenges educators to critically examine the school culture for policies and practices rooted in anti-Blackness. Education policy is a site of anti-Blackness which means that policies are entrenched in "ideologies, discourses, representations, (mal)distribution of material resources, and physical and psychic assaults on Black bodies in schools" (Dumas, 2016, p. 16). Any attempt at restorative practices that fails to acknowledge anti-Blackness in school risks creating environments where the only thing being restored, or maintained, is a system of inequity that has negative consequences for young adult Black girls.

Teacher preparation programs, particularly those preparing educators to work in urban schools with sizable Black student populations, should include coursework on YPAR, critical race theory, and/or similar approaches that center Black youth and their experiences in the construction of knowledge. An actionable first step is to evaluate current course requirements for teacher candidates to determine how, if at all, teachers are being prepared to engage with students, especially young adult Black girls, as co-researchers. In addition, school administrators and in-service teachers should take steps to deeply understand the context in which they teach. This might involve hosting community listening sessions with students, families, and residents in the neighborhood surrounding the school as well as neighborhoods from which students travel to the school. Such meetings would be an opportunity to learn from the community what values, traditions, and approaches to teaching and learning could be restored in a school setting and should therefore inform school policies. Finally, educators must learn to listen to Black girls, hear Black girls, protect Black girls, and center Black girls in their learning. This is especially important for young adult Black girls who are legal adults in high school settings and are learning, by the actions and inactions of their educators, how much their lives and learning matter in school.

\section{Notes On The Contributor}


Dr. Iesha Jackson is an Assistant Professor of Teacher Education in the Department of Teaching and Learning at the University of Nevada, Las Vegas. Her research calls attention to the need for equity-based reforms in education practices and policies across the secondary through post-secondary spectrum. Her work centers on examining methods to improve educational experiences for Black and Latinx students and teachers in urban schools. In order to address this, her research is situated in three main areas: student voice, culturally relevant and sustaining pedagogies, and equity-based, macro-level education policies.

\section{References}

American Arbitration Association. (1997). Model standards of conduct for mediators. Journal of the National Association of Administrative Law Judiciary, 17(2), 323-331. https://digitalcommons.pepperdine.edu/naalj/vol17/iss $2 / 9$

Bell, D. A. (1992). Faces at the bottom of the well: The permanence of racism. Basic Books.

Bell, D. A. (1995). Brown v. Board of Education and the interest convergence dilemma. In K. Crenshaw, N. Gotanda, G. Peller, \& K. Thomas (Eds.), Critical race theory: The key writings that formed the movement (pp. 2028). The New Press.

Coles, J. A., \& Powell, T. (2020). A BlackCrit analysis on Black urban youth and suspension disproportionality as anti-Black symbolic violence. Race

Ethnicity and Education, 23(1), 113-133. https://doi.org/10.1080/13613324.2019.1631778

Collins, P. H. (2019). Intersectionality as critical social theory. Duke University Press.

Crenshaw, K. (1991). Mapping the margins: Intersectionality, identity politics, and violence again women of color. Stanford Law Review, 43(6), 12411299. https://doi.org/10.2307/1229039

Delgado, R., \& Stefancic, J. (2012). Critical race theory: An introduction. New York University Press.

Dettwiller, S. (2019). Sticks and stones: How school-based peer mediation can reduce bullying in public schools. American Journal of Mediation, 12, 7295. http://www.americanjournalofmediation.com/Article\%203\%20\%20STACEY\%20DETTWILLER\%20o-Sticks\%20and\%20Stones.pdf 
Dixson, A. D., \& Rousseau Anderson, C. (2018). Where are we? Critical race theory in education 20 years later. Peabody Journal of Education, 93(1), 121-131. https://doi.org/10.1080/0161956X.2017.1403194

Dumas, M. J., \& Ross, K. M. (2016). 'Be real Black for me': Imagining BlackCrit in education. Urban Education, 51(4), 415-442. https://doi.org/10.1177/0042085916628611

Dumas, M. J. (2014). 'Losing an arm': Schooling as a site of black suffering. Race Ethnicity and Education, 17(1), 1-29. https://doi.org/10.1080/13613324.2013.850412

Dumas, M. J. (2016). Against the dark: Antiblackness in education policy and discourse. Theory Into Practice, 55(1), 11-19. https://doi.org/10.1080/00405841.2016.1116852

Evans-Winters, V. E. (2007). Teaching Black girls: Resiliency in urban classrooms. Peter Lang.

Evans-Winters, V. E. (2017). Flipping the script: The dangerous bodies of girls of color. Cultural Studies $\leftrightarrow$ Critical Methodologies, 17(5), 415-423. https://doi.org/10.1177/1532708616684867

González, T. (2012). Keeping kids in schools: Restorative justice, punitive discipline, and the school to prison pipeline. Journal of Law and Education, 41(2), 281-235.

Jenkins, D. A. (2021). Unspoken grammar of place: Anti-Blackness as a spatial imaginary in education. Journal of School Leadership, (1-2), 107-126. https://doi.org/10.1177/1052684621992768

Johnson, D. W., \& Johnson, R. T. (1996). Conflict resolution and peer mediation programs in elementary and secondary schools: A review of the research. Review of Educational Research, 66(4), 459-506. https://doi.org/10.3102\%2F00346543066004459

Lindsay, P. (1998). Conflict resolution and peer mediation in public schools: What works? Mediation Quarterly, 16(1), 85-99. https://doi.org/10.1002/crq.3890160109

Losen, D. J, \& Whitaker, A. (2020). 11 million days lost: Race, discipline, and safety at U.S. public schools. The Center for Civil Rights Remedies and The American Civil Liberties Union of Southern California. https://www.aclu.org/report/11-million-days-lost-race-discipline-andsafety-us-public-schools-part-1

Klein, R. (2016). Keeping our kids in school and out of court: Rooting out school suspension hearings and new alternative. Cardozo Journal of Conflict Resolution, 17(2), 633-657.

Majors, Y. J. (2015). Shoptalk: Lessons in teaching from an African American hair salon. Teachers College Press. 
McArthur, S. A., \& Lane, M. (2019). Schoolin'Black girls: Politicized caring and healing as pedagogical love. The Urban Review, 51(1), 65-80.

https://doi.org/10.1007/s11256-018-0487-4

Morris, E. W. (2007). Ladies or loudies?: Perceptions and experiences of Black girls in classrooms. Youth \& Society, 38(4), 490-515. https://doi.org/10.1177/0044118X06296778

Morris, M. W. (2012). Race, gender, and the "school to prison pipeline": Expanding our discussion to include Black girls. African American Policy Forum. http://schottfoundation.org/resources/race-gender-and-schoolprison-pipeline-expanding-our-discussion-include-black-girls

Morris, M. W. (2019). Sing a rhythm, dance a blues: Education for the Liberation of Black and Brown Girls. The New Press.

Morrison, B. (2005). Restorative justice in schools. In E. Elliot \& R. M. Gordon (Eds.), New directions in restorative justice: Issues, practices, evaluation (pp. 26-52). Willan Publishing.

Nix, C. L., \& Hale, C. (2007). Conflict within the structure of peer mediation: An examination of controlled confrontations in an at-risk school. Conflict Resolution Quarterly, 24(3), 327-348. https://doi.org/10.1002/crq.177

New York State Department of Education. (2015). school enrollment. http://data.nysed.gov/enrollment.php?year=2014\&instid= Institution name and ID redacted to preserve anonymity of research site.

NYC Department of Education. (2021). Transfer high schools. https://www.schools.nyc.gov/enrollment/other-ways-to-graduate/transferhigh-schools

Parker, L. (2017). Schools and the no-prison phenomenon: Anti-Blackness and secondary policing in the Black Lives Matter era. Journal of Educational Controversy, 12(1), 1-24. https://cedar.wwu.edu/jec/vol12/iss1/11

Schwartz-Shea, P. (2006). Judging quality: Evaluative criteria and epistemic communities. In D. Yanow \& P. Schwartz-Shea (Eds.), Interpretation and method: Empirical research methods and the interpretative turn (pp. 89113). Routledge.

Solórzano, D. G., \& Yosso, T. J. (2002). Critical race methodology: Counterstorytelling as an analytical framework for education research. Qualitative Inquiry, 8(1), 23-44. https://doi.org/10.1177/107780040200800103

Tate, W. F. (1997). Critical race theory and education: History, theory, and implications. Review of Research in Education, 22(1), 195-247. https://www.jstor.org/stable/1167376

The African American Policy Forum. (n.d.). \#SayHerName in memoriam. https://www.aapf.org/in-memorium

Wadhwa, A. (2013). Race, discipline, and critical restorative justice in two urban high schools (Order No. 3579002). Available from ProQuest Dissertations 
\& Theses Global. (1503793034). Retrieved from http://ezproxy.library.unlv.edu/login?url=https://search.proquest.com/docv iew/1503793034? accountid $=3611$

Watson, T. N. (2016). "Talking back": The perceptions and experiences of Black girls who attend City High School. The Journal of Negro

Education, 85(3), 239-249.

https://doi.org/10.7709/jnegroeducation.85.3.0239

Yin, R. (2009). Case study research: Design and methods (4th ed.). Sage. 